\title{
THE STABILITY OF ECONOMIC BASE MULTIPLIERS: SOME EMPIRICAL EVIDENCE
}

\author{
Randolph C. Martin and Harry W. Miley, Jr.*
}

\section{Introduction}

Few techniques of regional analysis have received as much criticism while being used as frequently as economic base analysis. There is little doubt that the high costs of more comprehensive techniques such as survey based inputoutput studies contribute to the popularity of this approach. One of the major criticisms of economic base as a technique of impact analysis and regional forecasting is that the related base multiplier varies over time. ${ }^{1}$ Interestingly however, this rather widely accepted criticism of the instability of the base multiplier is backed by a relatively small amount of empirical evidence. Also, what empirical evidence does exist is not always supportive of the instability hypothesis.

Probably the most cited study on the stability issue is Kansas City (1952) where base multipliers for Wichita were found to vary dramatically for several time periods. Prior to the Kansas City study, Hildebrand and Mace (1950) observed that base multipliers calculated for the Los Angeles area vary widely over an eight year period. Garnick (1969) also found variations in the base ratios for an early version of BEA's economic areas but in a later work (Garnick, 1970) using earnings data for Nebraska, he showed that the base ratios were stable over short periods of time. In addition to Garnick's 1970 results, there have been several other studies providing evidence that the multiplier is relatively stable over time. ${ }^{2}$ The evidence is thus inconclusive.

Unfortunately, the majority of the empirical work on this issue has been hindered by the lack of a broad enough data base. Some studies cover a large number of areas but are for only one or two time periods. The few studies that have analyzed time series data have been for

*University of South Carolina, Columbia. relatively unique areas or isolated regions. Because of this and the inconclusive results to date, both Isserman (1977) and Richardson (1978) have called for further research on the stability of the economic base multiplier.

In what follows, Section II briefly examines economic base theory and the related multiplier concept. Emphasis is placed on the various "propensities" which conceptually determine the size and thus stability of the multiplier. Section III utilizes a large pooled time series-cross section data set to examine the stability of the traditionally defined economic base multiplier. In Section IV, various hypotheses concerning factors which could cause variations in the multiplier over time are tested. Finally, Section V summarizes the findings and their implications for the usefulness of such multipliers.

\section{Economic Base Theory and Multipliers}

The traditional specification of an economic base model is well known. Using regional income as a measure of economic activity, ${ }^{3}$ the fundamental assumption of export base analysis can be expressed as follows:

$$
\begin{aligned}
\text { where } & \\
\text { TPI } & =\mathrm{f}(\mathrm{TXI}) \\
\text { TPI } & =\text { Total Personal Income in the Area } \\
\text { TXI } & =\text { Total Export Income in the Area } \\
\text { TLI } & =\text { Total Local Income in the Area } \\
\text { and } & \\
\text { TPI } & =\text { TLI }+ \text { TXI }
\end{aligned}
$$

The traditional specification of the export base multiplier can easily be derived within this framework as the ratio of total regional income to export income:

$$
\text { Economic Base Multiplier }=\frac{\text { TPI }}{\text { TXI }}
$$

While export income is derived from exogenous markets, local income is a function of 
export income and is derived locally by a two step process. First, sales to buyers outside the region generate labor and business earnings for the producers of these goods and services within the region. The recipients of these earnings spend a portion of their income on goods and services produced locally which creates sales dollars for local consumption goods and services. Tiebout (1962) calls this portion of an additional dollar of income that is spent on locally produced goods and services the propensity to consume locally $\left(\mathbf{P}_{c}\right)$. A second influence on the level of local income is that a portion of these sales dollars spent locally remain within the local economy and become local income. Tiebout calls this portion of local income consumption that remains as local income the propensity of the local sales dollar to remain as local income $\left(\mathrm{P}_{\mathrm{s}}\right)$.

Thus the total effect of an increase in exports can be determined by summing the increase in local income remaining in the area resulting from successive rounds of spending. This can be expressed as follows:

$$
\begin{aligned}
\mathrm{CHTPI}= & \text { CHTXI } *\left(\mathrm{P}_{\mathrm{c}}^{*} \mathrm{P}_{\mathrm{a}}\right)+\mathrm{CHTXI} *\left(\mathrm{P}_{\mathrm{c}} *(3)\right. \\
& \left.\mathrm{P}_{\mathrm{s}}\right)^{2}+\mathrm{CHTXI}^{2} *\left(\mathrm{P}_{\mathrm{c}} * \mathrm{P}_{\mathrm{s}}\right)^{3}+\ldots+ \\
& \text { CHTXI } *\left(\mathrm{P}_{\mathrm{c}} * \mathrm{P}_{\mathrm{a}}\right)^{\mathrm{n}}
\end{aligned}
$$

where

$$
\begin{aligned}
\text { CHTPI }= & \text { Change in Total Personal Income } \\
\text { CHTXI }= & \text { Exogenous Change in Export } \\
& \text { Income } \\
\mathbf{n}= & \begin{array}{l}
\text { Number of successive rounds of } \\
\text { spending }
\end{array}
\end{aligned}
$$

Fortunately, (3) exhibits a geometric progression and can be rewritten as:

$$
\text { CHTPI }=\text { CHTXI } * \frac{1}{\left(1-\left(\mathbf{P}_{\mathrm{c}} * \mathbf{P}_{\mathrm{s}}\right)\right)}
$$

and therefore the multiplier can be expressed as:

$$
\text { Multiplier }=\frac{1}{\left.\left(1-\mathrm{P}_{\mathrm{c}} * \mathrm{P}_{\mathrm{s}}\right)\right)}=\frac{\mathrm{TPI}}{\mathrm{TXI}}
$$

It is evident from (5) that the magnitude of the multiplier depends on the size of $P_{c}$ and $P_{s}$. The larger these propensities, the larger the multiplier. Also, any factors that lead to variations in the values of the propensities over time will of course lead to instability in the multiplier. We now turn to a consideration of those conditions discussed in the literature which could cause changes in $P_{c}$ and $P_{s}$ over time for a region.

The level of aggregate income is mentioned far more often than any other single factor as having an important influence on the propensities implicit in the multiplier. Such discussion is found in Blumenfeld (1955), Tiebout (1962), Leven (1964) and others. While presented in various forms, the idea is that larger aggregate regional incomes will increase local consumption's share of total expenditures. As some markets approach a certain threshold size, economies of scale make local production possible where the good (or service) was previously imported. This of course leads to an increase in the propensity to consume locally, and thus, the multiplier.

It has also been argued that offsetting the expected positive relationship between the multiplier and total income is a negative effect resulting from increasing per capita income. A negative effect is possible because higher per capita income levels in an area could result in a greater propensity to save and purchase luxury goods, which are most likely to be imported. This has a depressing effect on the multiplier because the greater the propensity to save and to import, the lower the propensity to consume local goods, $\mathbf{P}_{\mathrm{c}}$, and the smaller the multiplier. On the other hand, larger per capita income means (ceterus paribus) larger aggregate incomes. As discussed above, this would create greater overall demand for all goods and services and enable an area to support a larger number of activities. This would result in larger multipliers. Thus, the direction of the influence of per capita income on the multiplier is questionable.

Along similar lines, many have suggested the level of population as a factor influencing the size and stability of these propensities and the related multiplier. North (1955), Tiebout (1962), Isard (1960), Andrews (1953), DeRooy (1980) and Blumenfeld (1955) all argue for an expected positive relationship between an area's population and the size of the multiplier. As population increases, certain markets reach threshold levels and the propensity to consume local goods $\left(\mathbf{P}_{\mathrm{c}}\right)$ and the propensity of a local sales dollar to remain as local income $\left(P_{s}\right)$ both increase. Empirical support for this is provided by Harvey (1973) and Pfouts (1957).

Another factor which has received considerable attention is the degree of diversification. In 
this situation, if economic diversity leads to the substitution of locally produced goods and services for imported goods and services, then both $P_{c}$ and $P_{s}$ would increase, as would the multiplier. For the same reasons, if the industrial structure of an economy shifts from being more heavily dominated by manufacturing to less manufacturing oriented, the stability of multiplier may also be affected. As the manufacturing sector declines in relative importance, the nonmanufacturing activities that are increasing in relative importance will most likely be service or trade related. These trade and service activities are generally local as opposed to export activities. As a result of this expansion of local services, both $P_{c}$ and $P_{s}$ would increase, as would the multiplier. The import replacing nature of industrialization and diversification is considered by Sirkin (1959), Blumenfeld (1957), Garnick (1970), McGilvany and Simpson (1969) and Conway (1977).

Of all the other factors discussed in the literature as possibly influencing the multiplier, ${ }^{4}$ only the level of aggregate, exogenous demand has received anything more than occasional or isolated attention. DeRooy (1980), Harvey (1973), Blumenfeld (1955), Andrews (1953), Garnick (1970), Isard (1960), Conway (1977) and Tiebout (1956) have made reference to the influence of exogenous demand or fluctuations in exogenous demand on the size and stability of the multiplier. Here, rapid expansion in regional output (resulting from external demand changes) could lead to input shortages which force the local economy to external sources of supply. This would reduce the propensity to consume local goods $\left(P_{c}\right)$ and thus, the size of the economic base multiplier.

Aggregate income levels, per capita income, population size, degree of industrial diversification and changes in exogenous demand are then the most often mentioned and most generally accepted factors which could lead to variations in a region's economic base multiplier. As indicated in the introduction, however, the empirical evidence on the stability issue and on the factors which could contribute to instability is rather underdeveloped. The remainder of this paper will attempt to improve this situation.

\section{Empirical Evidence on the Stability Issue}

As previously noted, one of the major problems with prior work on the stability issue has been the lack of a broad enough data base. For this study, annual personal income data at the two-digit SIC-Code level from the Bureau of Economic Analysis, U.S. Department of Commerce are used. The information is for 181 BEA Economic Areas and covers from 1959 to 1979 (except 1960, 1961, 1964 and 1965 for which data are not available. $)^{5}$ Thus, the series covers a time span of 21 years for 181 separate geographic areas.

In order to make the analysis of the 181 Economic Areas more manageable, the data are pooled into eight groups corresponding as closely as possible to BEA's eight regions (see Figure 1). While the official BEA Regions are defined by state boundaries, the regions as used here include those BEA Economic Areas that most closely approximate the official BEA regional boundaries. ${ }^{6}$ These relatively large data sets then make it possible to study areas of substantially different sizes and economic structures over a fairly extended period of time.

Calculating the traditional economic base multiplier for a geographic area requires that the area's total personal income be separated into two categories; that generated by export activity and that derived from local sources. Since this study involves large cross-section time series estimates, it was necessary to utilize one of the indirect classification schemes. The most often used of these techniques are the location quotient (LQ) and the minimum requirement technique (MRT). These approaches have been discussed extensively in the literature and thus, will not be reviewed at this point. ${ }^{7}$ Briefly, however, Isserman argues that of the four major indirect techniques, the assumption, econometric, MRT and LQ methods, only the LQ and MRT methods have any theoretical justification. He states that "one procedural guideline would be to avoid use of the MRT for regions that are known to be highly specialized" (Isserman, 1980, p. 178). It

Figure 1.

$\begin{array}{ll}\quad \text { Regions } & \text { BEA } \text { Areas Included } \\ \text { 1. Northeast } & 1-6 \\ \text { 2. Mideast } & 7-20 \\ \text { 3. Southeast } & 21-62 \text { and } 109-118 \\ \text { 4. Great Lakes } & 63-94 \\ \text { 5. Plains } & 95-108 \text { and } 139-152 \\ \text { 6. Southwest } & 119-138 \text { and } 160-162 \\ \text { 7. Rocky Mountain } & 153-159 \text { and } 165-167 \\ \text { 8. Far West } & 163-164 \text { and } 168-181\end{array}$


is very likely that many of the $181 \mathrm{BEA}$ areas have highly specialized economic structures. However, such detailed local knowledge of these 181 areas is not readily ascertained. Without such local knowledge of these areas, the MRT is not considered appropriate for this analysis. So, location quotients were calculated (using personal income data) for each area and each time period and these LQs were then used to classify local and export income.

With export and local income delineated, it is then possible to begin to examine the multiplier stability issue. ${ }^{8}$ First, utilizing a covariance model and Chow test, the above data are used to examine whether or not there are structural shifts over time in the relationship between export and local income. If such shifts are observed, then it can be assumed that economic base multipliers are not stable over time. The seventeen annual observations for each BEA area are pooled and the following regression model is estimated for each of the eight regions:

$$
\begin{gathered}
\mathrm{TLI}=\mathrm{b}_{1}+\mathrm{b}_{2} * \mathrm{TXI}+\mathrm{v}_{2}^{*} \mathrm{Z}_{2}+\mathrm{v}_{3} * \mathrm{Z}_{3} \\
+\ldots+\mathrm{v}_{\mathrm{n}} * \mathrm{Z}_{\mathrm{n}}+\mathrm{e}
\end{gathered}
$$

where

$$
\begin{aligned}
\text { TLI } & =\text { Total Local Income } \\
\text { TXI } & =\text { Total Export Income } \\
\mathbf{Z}_{\mathrm{i}} & =1 \text { for the ith area, } \mathrm{i}=1, \ldots, \mathbf{n} \\
& =0 \text { otherwise } \\
\mathrm{e} & =\text { error term }
\end{aligned}
$$

and $b_{1}, b_{2}, v_{2}, v_{3}, \ldots, v_{n}$ are estimated parameters of the model.

Equation (6) is estimated over the first half of the period (1959-1970), over the second half of the period (1971-1979) and over the entire period (1959-1979) for each region. The results of the Chow tests for the homogeneity of $b_{2}$ over different time periods indicate that the coefficient is not stable over the 1959-1979 time period in any region. As Table 1 indicates, the null hypothesis that the parameter $b_{2}$ is constant over the two time periods must be rejected. ${ }^{9}$ The critical $F$ value is not above 3.0 in any region while all of the calculated $F$ values from the Chow tests are above 12.0 and four are over 19.0. The $F$ tests clearly indicate that $b_{2}$ is not statistically equivalent between the 19591970 period and the $1971-1979$ period. This can be interpreted as an indication that there are structural shifts in the relationship between total export income and total local income during the 21 year time period and thus, that the multiplier is not stable over time. ${ }^{10}$

To provide additional evidence on the stability of the multiplier, a second test is performed for each region. Here, Equation (7) is estimated over the entire time period to determine the sign and significance of the variable TIME. If the economic base multiplier varies systematically over time, then time should explain some of this variation. A proxy for time (TIME) is used as an explanatory variable in the following model where the dependent variable is now

\begin{tabular}{|c|c|c|c|c|c|c|c|c|}
\hline & \multicolumn{8}{|c|}{ Region } \\
\hline & $\mathrm{NE}$ & $\mathrm{ME}$ & $\mathrm{SE}$ & GL & PL & SW & RM & FW \\
\hline RRSS & $5.63 \mathrm{E} 13$ & 21.32 E14 & $19.49 \mathrm{E} 13$ & 8.96 E14 & 21.16 E13 & 19.94 E13 & 4.95 E13 & 11.40 E14 \\
\hline $\begin{array}{l}\text { URSS } \\
1\end{array}$ & .35 E13 & $1.68 \mathrm{E} 14$ & $1.07 \mathrm{E} 13$ & .45 E14 & .87 E13 & $.50 \mathrm{E} 13$ & .17 E13 & $.52 \mathrm{E} 14$ \\
\hline $\begin{array}{l}\text { URSS } \\
2\end{array}$ & $2.33 \mathrm{E} 13$ & $5.28 \mathrm{E} 14$ & $6.78 \mathrm{E} 13$ & 3.42 E14 & 7.06 E13 & 8.44 E13 & $2.33 \mathrm{E} 13$ & $4.51 \mathrm{E} 14$ \\
\hline $\mathbf{S}$ & $2.67 \mathrm{E} 13$ & 6.96 E14 & 7.85 E13 & 3.87 E14 & 7.92 E13 & 8.94 E13 & $2.50 \mathrm{E} 13$ & 5.03 E14 \\
\hline $\mathbf{k}$ & 6 & 14 & 52 & 32 & 28 & 23 & 10 & 16 \\
\hline D.F. & 88 & 180 & 778 & 478 & 418 & 343 & 148 & 238 \\
\hline $\mathbf{F}$ & 12.57 & 24.75 & 21.78 & 19.09 & 24.09 & 17.59 & 13.15 & 17.73 \\
\hline $\begin{array}{l}\text { Crit } \\
\text { F }\end{array}$ & 2.87 & 2.12 & 1.57 & 1.74 & 1.74 & 1.88 & 2.37 & 2.09 \\
\hline
\end{tabular}
the traditional specification of the base multiplier:

$$
\begin{aligned}
\frac{\text { TPI }}{\text { TXI }=b_{1}+v_{2} Z_{2}+} & v_{3} Z_{3}+\ldots+V_{n} Z_{n} \\
& + \text { gTIME }+e
\end{aligned}
$$

TABLE 1.

Chow Test Summary Statistics 
where

$$
\begin{aligned}
\text { TPI } & =\text { Total Income in the Area } \\
\text { TXI } & =\text { Total Export Income in the Area } \\
\mathbf{Z}_{\mathrm{i}} & =1 \text { for the ith Area, } \mathrm{i}=1, \ldots, \mathrm{n}-1 \\
& =0 \text { otherwise } \\
\text { TIME } & =1 \text { for } 1959 \\
& =4 \text { for } 1962 \\
& : \\
& \bullet \\
& =21 \text { for } 1979 \\
\mathbf{e} & =\text { error term } \\
\mathbf{n} & =\text { number of Areas }
\end{aligned}
$$

and $b_{1}, v_{2}, \ldots v_{n}$ and $g$ are estimated parameters.

As seen in Table 2, the variable TIME has a positive sign and is significant at the 1 percent level in all eight regions. This indicates that a considerable amount of the variation in the multiplier is explained by the variable TIME (along with the regional dummy variables). As Table 2 shows, the R-squares of Equation (7) averaged above 0.9 and in only one region, the Rocky Mountain Region, was it below 0.9. These results support the conclusions of the Chow tests and lend further evidence that the multiplier varies over time. The positive sign for this coefficient is consistent with the popular hypothesis that multipliers tend to increase in size as regions mature (i.e., with the passage of time).

\section{Sources of Instability}

The results presented in the preceding section indicate that the multiplier does indeed vary, at least over the time period considered. These tests, however, do not deal with the source of this instability. The objective of this

TABLE 2.

Results For The Variable Time in Equation (7)

\begin{tabular}{ccrc}
\hline Region & Coefficient & T Values & R-Squares \\
\hline NE & .050946 & 10.0128 & .96 \\
ME & .026382 & 3.9466 & .97 \\
SE & .051065 & 27.0715 & .95 \\
GL & .024163 & 10.1148 & .96 \\
PL & .041003 & 14.0548 & .97 \\
SW & .039285 & 10.9374 & .90 \\
RM & .056485 & 7.7119 & .85 \\
FW & .057859 & 14.0226 & .97 \\
\hline
\end{tabular}

section then is to examine the factors which may be contributing to this variation. Section II provided a brief review of the most often discussed causes of this instability and will serve as the basis for the empirical model which follows.

To examine the role played by each of these factors, Equation (7) is re-estimated with TIME being replaced by variables reflecting per capita income, population, industrial structure and changes in exogeneous, aggregate demand. ${ }^{11}$ The estimating equation is then:

$$
\begin{aligned}
\text { TPI }= & \mathrm{b}_{1}+\mathrm{C}_{1} \mathrm{PCI}+\mathrm{C}_{2} \mathrm{POP}+\mathrm{C}_{3} \text { IND } \\
& +\mathrm{C}_{4} \mathrm{CHGNP}+\mathrm{v}_{2} \mathrm{Z}_{2}+\mathrm{v}_{3} \mathrm{Z}_{3}+\ldots+ \\
& \mathrm{v}_{\mathrm{n}} \mathrm{Z}_{\mathrm{n}}+\mathrm{e}
\end{aligned}
$$

where TPI, TXI, $\mathrm{Z}$ and e are as previously defined and

$$
\begin{aligned}
\text { PCI }= & \text { Per capital income } \\
\text { POP }= & \text { Population } \\
\text { IND }= & \text { Percent of income from } \\
& \text { manufacturing } \\
\text { CHGNP }= & \text { Percent change in real GNP }
\end{aligned}
$$

and PCI, POP, IND are all at BEA area level.

The role and intent of the first two explanatory variables is clear and needs no discussion. IND is a measure of the degree of industrialization. While more sophisticated methods of measuring industrialization exist, data limitations and the large number of areas in this data set prohibit their use. However, when personal income is classified into just aggregate import and local shares, IND as defined here is an appropriate proxy for industrialization. The hypothesis here is that the higher the degree of industrialization, the smaller will be the proportion of goods and services produced for local consumption, because the smaller will be the service and trade sector. The change in real GNP (CHGNP) is intended to serve as a proxy for variations in exogenous demand. Thus, increases in real GNP are expected to result in input shortages, increases in the propensity to import, and smaller multipliers. A negative relationship between CHGNP and the multiplier is then anticipated.

The relevant results of estimating Equation (8) for each of the eight regions are shown in Table 3. As noted earlier, the direction of the influence of PCI on the multiplier was in question. It appears from Table 3 that in all but the Northeast (NE) and Mideast (ME) regions, 
TABLE 3.

Estimated Results: Equaiton (8)

\begin{tabular}{|c|c|c|c|c|c|}
\hline \multirow[b]{2}{*}{ Region } & \multicolumn{5}{|c|}{ Variable } \\
\hline & PCI & POP & Ind & CHCNP & $\mathbf{R}^{2}$ \\
\hline $\mathrm{NE}$ & $\begin{array}{l}.000021 \\
(1.02)\end{array}$ & $\begin{array}{c}-9.49 \mathrm{E}-7^{*} \\
(-2.68)\end{array}$ & $\begin{array}{l}-12.9^{*} \\
(-7.76)\end{array}$ & $\begin{array}{c}-.457 \\
(-.80)\end{array}$ & .97 \\
\hline ME & $\begin{array}{r}-.00008^{*} \\
(-5.24)\end{array}$ & $\begin{array}{l}\text { 8.27 E-7* } \\
(5.9)\end{array}$ & $\begin{array}{l}-8.97^{*} \\
(-7.61)\end{array}$ & $\begin{array}{l}.149 \\
(.35)\end{array}$ & .98 \\
\hline SE & $\begin{array}{l}.00014 * \\
(17.58)\end{array}$ & $\begin{array}{r}-2.1 \mathrm{E}-7 \\
(-1.48)\end{array}$ & $\begin{array}{l}1.55^{*} \\
(2.56)\end{array}$ & $\begin{array}{l}-1.22^{*} \\
(-5.17)\end{array}$ & .94 \\
\hline GL & $\begin{array}{l}.000014 * \\
(1.75)\end{array}$ & $\begin{array}{l}3.77 \text { E-7 } \\
(1.54)\end{array}$ & $\begin{array}{r}-4.33^{*} \\
(-6.56)\end{array}$ & $\begin{array}{c}-.69^{*} \\
(-2.45)\end{array}$ & .96 \\
\hline PL & $\begin{array}{l}.000079 * \\
(7.86)\end{array}$ & $\begin{array}{c}-1.82 \mathrm{E}-8 \\
(-.04)\end{array}$ & $\begin{array}{l}3.45^{*} \\
(3.81)\end{array}$ & $\begin{array}{c}-.96^{*} \\
(-2.69)\end{array}$ & .96 \\
\hline SW & $\begin{array}{l}.000065^{*} \\
(5.40)\end{array}$ & $\begin{array}{c}-1.45 \mathrm{E}-7 \\
(-.77)\end{array}$ & $\begin{array}{l}5.39 * \\
(8.33)\end{array}$ & $\begin{array}{l}-1.9^{*} \\
(-4.74)\end{array}$ & .9 \\
\hline $\mathbf{R M}$ & $\begin{array}{l}.00011^{*} \\
(5.10)\end{array}$ & $\begin{array}{l}2.81 \mathrm{E}-7 \\
(.56)\end{array}$ & $\begin{array}{c}8.98^{*} \\
(11.70)\end{array}$ & $\begin{aligned}-.70 \\
(-1.06)\end{aligned}$ & .91 \\
\hline FW & $\begin{array}{l}.00008 \\
(6.29)\end{array}$ & $\begin{array}{l}7.99 \text { E-7* } \\
(6.44)\end{array}$ & $\begin{array}{l}-1.04 \\
(-1.12)\end{array}$ & $\begin{array}{l}.69 \\
(-1.46)\end{array}$ & .97 \\
\hline
\end{tabular}

*Significant at the $5 \%$ level.

$t$ values in parentheses.

higher per capita incomes result in larger shares of local consumption (presumably through import substitution) and thus larger multipliers. The negative and significant sign for the Mideast region is interesting in that the Mideast has the second highest average per capita income and the highest average population of the eight regions. Tiebout (1962) argues that at some point, higher incomes could lead to changes in consumption patterns, especially toward increased purchases of luxury goods. And, these types of goods are most likely to be imported.

The sign and significance of population (POP) is less consistent across regions than PCI. POP is significant in only three of the eight regions, and positive, as expected, in just two of these regions. A larger population in an area was hypothesized as having a positive impact on the size of an area's multiplier by making the area generally more self-sufficient. As can be seen in Table 3, this occurred in the Mideast (ME) and Far West (FW) regions. However, in the Northeast (NE) region, population has a negative sign and is significantly different from zero.

In all but the Far West (FW), the degree of industrialization (IND) is significant. In three of the regions where IND is significant, it has the expected negative sign, while in the other four regions IND has a positive sign. It was hypothesized that the higher the degree of industrialization of an area, the smaller proportion of total goods and services would be produced for local consumption since the majority of manufacturing goods are produced for export and not for local consumption (industrialization being equated with manufacturing). This is apparently the case in the three regions where IND is negative and significantly different from zero.

The exact cause of the different signs in the eight regions is difficult to identify. However, the regions in which IND had one sign or the other have several similar characteristics. The regions in which IND is negative (Northeast, Mideast and Great Lakes) are generally more highly developed, older and more heavily populated than the regions in which IND has a positive sign (Southeast, Plains, Southwest and Rocky Mountain).

The change in real Gross National Product (CHGNP) is significant in four of the eight regions (Southeast, Great Lakes, Plains and Southwest). As hypothesized, the signs of the significant coefficients are negative. As mentioned previously, Isard and others have suggested that a rapid expansion in the economy could lead to input shortages, forcing the local economy to turn to external sources of supply. This would have the effect of increasing a 
region's overall propensity to import which could result in a negative relationship between the business cycle and the multiplier. With the exception of the Rocky Mountain Region, the regions in which CHGNP is not significant have higher incomes and are more heavily populated than the regions in which CHGNP is significant. These regions would most likely have areas with more highly developed economies than those areas in the other four regions. The insignificance of CHGNP may be a result of the more developed areas being more self-sufficient and less sensitive to fluctuations in the national business cycle than the less developed areas (or because these areas have excess capacity).

The final task in this section is to provide some initial evidence on the relative importance of each variable in explaining variations in the economic base multiplier. To this end, Table 4 shows the calculated beta coefficients for each variable for each region. ${ }^{12}$ While the ranking of relative importance of the variables varies from region to region, population, degree of industrialization and per capita income rank first or second in six of the eight regions. POP is ranked first in four regions with IND ranking first in three. The least important of the four factors appears to be the proxy for fluctuations in exogeneous aggregate demand. CHGNP does not rank higher than third in any region and ranks as least important in six of the eight regions.

TABLE 4

Beta Coefficients*

\begin{tabular}{ccccc}
\hline & \multicolumn{4}{c}{ Coefficients } \\
\cline { 2 - 5 } Region & PCI & POP & IND & CHGNP \\
\hline \multirow{2}{*}{ NE } & 0.029 & -1.437 & -.367 & -.017 \\
& $(3)$ & $(1)$ & $(2)$ & $(4)$ \\
ME & -.083 & 2.124 & -.411 & .004 \\
& $(3)$ & $(1)$ & $(2)$ & $(4)$ \\
SE & .210 & -.104 & .100 & -.048 \\
& $(1)$ & $(2)$ & $(3)$ & $(4)$ \\
GL & .020 & .471 & -.275 & -.024 \\
& $(4)$ & $(1)$ & $(2)$ & $(3)$ \\
PL & .147 & -.014 & .270 & -.043 \\
SW & .118 & -.098 & .387 & -.081 \\
& $(2)$ & $(3)$ & $(1)$ & $(4)$ \\
RM & .178 & .111 & .425 & -.028 \\
& $(2)$ & $(3)$ & $(1)$ & $(4)$ \\
FW & .096 & 1.191 & -.042 & -.018 \\
& $(2)$ & $(1)$ & $(3)$ & $(4)$ \\
\hline
\end{tabular}

*Relative rank in parentheses.
V. Summary and Conclusions

This paper utilized a large pooled time seriescross section data set to examine the stability of the traditionally defined economic base multiplier. Previous research has resulted in inconclusive evidence on the stability issue. As such, the simple multiplier is unfortunately still used frequently as a long range forecasting technique. All evidence in the analysis conducted here points to the fact that over extended time periods (21 years), the multiplier is indeed unstable. This is supportive of the widely discussed criticism that the multiplier varies over time and suggests the analytical usefulness of such measures is limited to relatively short periods of time. Further, the results of Section IV indicate that the factors most often discussed as contributing to this variability do influence the size of the base multipliers. However, in many cases, the direction of the influence is not consistent across regions. There is thus some evidence that the manner in which population, per capita income and the other factors affect the multiplier may depend on the stage of development and economic structure of the region under consideration. This is certainly an area where further inquiry is warranted.

\section{FOOTNOTES}

${ }^{1}$ See for example Isard (1960), Richardson (1969), Richardson (1978) and Greenhut (1959).

2These include Garrison (1972), Billings (1969), and to a certain degree McGilvrary and Simpson (1969) and Leven (1964).

${ }^{3}$ Arguments favoring income as the appropriate measure of regional economic activity for this purpose can be found in Garnick (1970), Garrison (1973) and Pfister (1976).

"For a good listing of "other" factors see DeRooy (1980).

${ }^{5} \mathrm{BEA}$ Economic Areas are multicounty heterogenous regions. A detailed discussion of how these areas are delineated can be found in Bureau of Economic Analysis (1975). Data disaggregated at the 3 or 4-digit SIC level would have been preferred but disclosure problems and shorter time periods of availability made their use less desirable.

${ }^{6}$ Areas in Alaska and Hawaii were excluded.

${ }^{7}$ Isserman (1980) provides a good up-to-date critical review of these techniques.

${ }^{8}$ We are of course assuming that the LQ methodology has no consistent influence on temporal variations in the simple multiplier. Examination of this assumption is beyond the scope of this paper. Further, since the LQ approach is frequently used by practitioners, the conclusions of this paper remain relevant.

${ }^{9}$ Complete results of these estimations are available on requests from the authors.

${ }^{10}$ The focus of this paper is on the longer run stability issue (i.e., 21 years). The methodology suggested here, however, could be utilized to examine the stability of simple multipliers over short and intermediate time periods as well. 
${ }^{11}$ Due to the very high degree of collinearity between population and total personal income, income is not included as an explanatory variable. (The average simple correlation coefficient was .90 for the eight regions.)

${ }^{12}$ For an explanation of beta coefficients see Goldberger $(1964$, p. 197). The validity of these coefficients is conditional on the $X^{\prime} X$ inverse matrix being orthogonal. Examination of the partial correlation matrices indicates that the beta coefficients may be interpreted as relatively valid indicators of the contribution of the independent variables to variations in the dependent variable.

\section{REFERENCES}

Andrews, Richard B. "Mechanics of the Urban Economic Base: Historical Development of the Base Concept." Land Economics, XXIX (May, 1953), 161-167.

Billings, R.B. "Regional Defense Impact-A Case Study Comparison of Measurement Techniques." Journal of Regional Science, X (May, 1969), 199-216.

Blumenfeld, Hans. "Economic Base of the Metropolis." Journal of the American Institute of Planners. (Fall, 1955), 114-132.

Conway, R.S. "Changes in Regional 1-0 Coefficients and Regional Forecasting." Regional Science and Urban Economics, X (March, 1980), 153-171.

DeRooy, J. "Analysis of Public Employment Impact Multipliers in Depressed Areas." Growth and Change, Xi (April, 1980), 32-38.

Garnick, D.H. "Disaggregated Basic-Service Models and Regional Input-Output Models in Multiregional Projections." Journal of Regional Science, IX (February, 1969), 87-100.

Garnick, D.H. "Differential Regional Multiplier Models." Journal of Regional 'Science, X (February, 1970), 35-47.

Garrison, C.B. "Impact of New Industry: An Application of the Economic Base Multiplier to Small Rural Areas." Land Economics, XLVIII (1972), 329-337.

Goldberger, A. Econometric Theory, New York: Wiley, 1964.

Greenhut, M.L. "Comments on Economic Base Theory." Land Economics, XXXV (1959), 71-75.

Harvey, A.S. "Spatial Variation of Multipliers; Cross Sectional Analysis." Land Economics, XLIX (1973), 469-475.

Hildebrand, G.H. and Mace, A. "Employment Multipliers in an Expanding Industrial Market inLos Angeles County." Review of Economics and Statistics, XXXII (August, 1950), 241-249.

Isard, W. Methods of Regional Analysis: An Introduction to Regional Science. New York: Massachusetts Institute of Technology and Wiley, 1960.

Isserman, A.M. "The Location Quotient Approach to Estimating Regional Economic Impacts." Journal of American Institute of Planners, XIIII (January, 1977), 33-41.

Isserman, A.M. "Estimating Export Activity in a Regional Economy: A Theoretical and Empirical Analysis of Alternative Methods." International Regional Science Review, V (Winter, 1980), 155-184.

Kansas City Federal Reserve Bank. Monthly Review, (September, 1952), 1-7.

Leven, C.L. "Regional and Interregional Accounts in Perspective." Papers and Proceedings Regional Science Association, XIII (1964), 127-144.

McGilvray, S. and Simpson, D. "Some Tests of Stability in Interindustry Coefficients." Econometrica, XXXVII (April, 1969), 204-222.

Moody, H.T. and Puffer, F.W. "The Empirical Verification of the Urban Base Multiplier: Traditional and Adjustment Process Models." Land Economics, XLVI (February, 1970), 91-98.

North, D.C. "Location Theory and Regional Economic Growth." Journal of Political Economy, LXIII (June, 1955), 243-258.

Pfister, R.L. “On Improving Export Base Studies." Regional Science Perspectives, VI (1976), 104-116.

Pfouts, R.W. "An Empirical Testing of the Economic Base Theory." Journal of American Institute of Planners, XXIII (1957), 64-69.

Richardson, H.W. "The State of Regional Economics: Survey." International Regional Science Review, III (Winter, 1978), 1-48.

Richardson, H.W. Regional Economics. New York: Praeger, 1969.

Sirkin, G. "The Theory of Regional Economic Base." Review of Economics and Statistics, XLI (November, 1959), 426429.

Tiebout, C.M. The Community Economic Base Study. Committee for Economic Development, December, 1962.

Tiebout, C.M. "The Urban Base Reconsidered." Land Economics, XXXII (1956), 95-99. 